\title{
Method of Optimization and Multi-criteria Evaluation of Distributed Combined Cooling Heating and Power Energy System ${ }^{1}$
}

\author{
Xudong Wang ${ }^{1, a}$, Ling Jiang ${ }^{1, b}$, Jiancheng $\mathrm{Yu}^{1, \mathrm{c}}$, Yingqiu Wang ${ }^{1, \mathrm{~d}}$, and Yan $\mathrm{Q} \mathrm{i}^{1, \mathrm{e}}$ \\ ${ }^{1}$ State Grid Tianjin Electric Power Company, Tianjin 300010, China. \\ a158269975@qq.com, b409167116@qq.com, \\ c731862996@qq.com, ${ }^{\mathrm{d}} 1186292162 @ q q . c o m,{ }^{\mathrm{e}} 327422221 @ q q . c o m$
}

Keywords: distributed energy system (DES); combined cooling heating and power (CCHP); optimization design; evaluation criteria; criterion weight; information entropy.

\begin{abstract}
Different energy systems were developed on the basis of the major equipment of distributed energy systems (DES). According to the demand of loads, energy prices, and technical and financial information about optional technologies, using non-linear programming, an optimization model for DES was established. The optimum configuration, optimal operation scheme and evaluation criteria matrix were the results of the model. The information entropy was used to determine the weight distribution, then the multi-criteria comprehensive evaluation method was introduced. The results demonstrate that photovoltaic system is optimal scheme due to its lower cost, energy conservation and environmental protection.
\end{abstract}

\section{Introduction}

Using natural gas, renewable energy in multi-energies hybrid power systems is of great importance. The combination of Distributed Energy Systems (DES) and the centralized power generation system has also become an important future direction of power and energy industry [1].

DES contains a lot of equipment which can satisfy different kinds of cooling, heating and power loads simultaneously [2,3]; as a consequence, same kind of loads can be satisfied by different kinds of energy supplies [4]. Thus it is difficult to determine the capacity and operating mode of the equipment in an optimal way. Previous research almost focused on operational strategies developed in fixed mode, then studied characteristics of systems or determined the kind and the capacity of devices according to device parameters and energy demand [2,5].

An important factor influencing the development of the DES is an effective system evaluation method. In the previous studies, the evaluation was Primary Energy Ratio [6]. However, the only one index cannot be a reasonably accurate assessment of DES [7]. Obviously, different evaluation methods will yield different results of the evaluation, and it is difficult to determine which method is more accurate.

This paper establishes a nonlinear programming model which can optimize system configuration and operation of the program simultaneously. Considering system investment costs, annual operating costs, primary energy consumption, primary energy ratio, the annual emissions of $\mathrm{CO}_{2}$ and $\mathrm{NO}_{\mathrm{x}}$ and other performance criteria, that is to build the evaluation criteria system from the economic, energy and environmental aspects. According to the degree of difference between criteria, the objective weight of each criterion is determined by entropy principle.

\section{Energy system}

The most widely used DES are the internal combustion engine (gas turbine) cogeneration systems, photovoltaic systems, fuel cell systems, etc [8-10]. This paper mainly focuses on the five systems: the four mentioned before and the traditional system. These five systems are shown in Table 1. 
This paper mainly focuses on grid (The average efficiency of conventional coal-fired power plants is $36 \%$ and line loss rate is $7 \%$ ), internal combustion turbine, gas turbine, fuel cell, PV, gas boiler, absorption refrigeration, heat exchanger [11]. And the parameters such as equipment costs, operating costs, power efficiency and thermal efficiency can be acquired from reference books [12-14].

Table 1 Description of the energy systems

\begin{tabular}{ccc}
\hline Number & Systems & System components \\
\hline S1 & Traditional system & Grid + Air conditioning + Gas boiler \\
S2 & Photovoltaic system & Grid + PV panels + Air conditioning + Gas boiler \\
S3 & Fuel cell system & Grid + Fuel cell + Air conditioning \\
S4 & Gas turbine system & Grid + Gas turbine + Absorption refrigeration + Gas boiler \\
S5 & Internal combustion & Grid + Internal combustion turbine + Absorption refrigeration + \\
& engine system & Gas boiler \\
\hline
\end{tabular}

\section{Optimization Model}

\section{Objective function}

Most EDS are evaluated by economic criteria. This paper establishes an optimization model with the annual cost as the objective function. The cost covers annual investment in equipment $C_{\text {cap }}$, annual investment in operation and maintenance $C_{O \& M}$, annual fuel $\operatorname{cost} C_{\text {fuel }}$. The objective function is (1),

$$
\begin{gathered}
\min C_{\text {total }}=C_{\text {cap }}+C_{O \& M}+C_{\text {fuel }} \\
C_{\text {cap }}=\sum_{\text {tech }} I_{\text {nvtech }} C_{\text {aptech }} \frac{1}{1-(1+I)^{-L_{\text {ttech }}}} \\
C_{O \& M}=\sum_{\text {tech }} O_{\text {Mtech }} \sum_{m} \sum_{h} E_{\text {tech }, m, h} \\
C_{\text {fuel }}=\sum_{m} \sum_{h} V_{\text {gas }, m, h} P_{\text {gas }, m, h}
\end{gathered}
$$

where $I_{\text {nvtech }}$ is the cost of each device, $C_{\text {aptech }}$ is the optimization capacity of each device, $I$ is discount rate, $10 \%, L_{\text {ttech }}$ is the service life of equipment, $O_{\text {Mtech }}$ is operating costs of each device, $E_{\text {tech,m,h }}$ is hourly load of each device, $V_{g a s, m, h}$ is hourly gas consumption, $P_{g a s, m, h}$ is hourly gas price.

\section{Constraints}

Constraints include equality and inequality constraints. Inequality constraints are that in order to satisfy hourly cooling, heating and power load, energy supply is greater than energy demand. The inequality constraints are (5) to (7),

$$
\begin{gathered}
E_{d e s, o, m, h}+E_{e p, m, h} \geq E_{d e m, m, h} \\
C_{d e s, o, m, h} \geq C_{d e m, m, h} \\
H_{d e s, o, m, h} \geq H_{d e m, m, h}
\end{gathered}
$$

where subscript des,o,m,h means hourly output, $e p, m, h$ means hourly demand, $E_{e p, m, h}$ is hourly power purchased, $E, C, H$ mean electricity, cooling and heat.

Equality constraints are related to energy conversion and energy consumption and production. They can be demonstrated by (8) to (13),

$$
\begin{gathered}
\frac{V_{g a s, m, h} L_{H V g a s}}{3.6}=E_{g a s, m, h} \\
E_{g a s, m, h}=E_{d e s, i, m, h} \\
E_{e q, i, m, h} \alpha_{e q}=E_{e q, o, m, h} \\
H_{e q, i, m, h} \beta_{e q}=H_{e q, o, m, h}
\end{gathered}
$$




$$
\begin{gathered}
C_{e q, i, m, h} C_{\text {OPeq }}=C_{e q, o, m, h} \\
H_{d e m, m, h}=H_{h w l, d e m, m, h}+H_{h l, d e m, m, h}
\end{gathered}
$$

where $V_{g a s, m, h}$ is hourly gas consumption, $L_{H V g a s}$ is gas calorific, $E_{g a s, m, h}$ is hourly heat supply, $E_{\text {des }, i m, h}$ is input heat, $\alpha_{e q}$ is electricity efficiency, $\beta_{e q}$ is heating efficiency, $C_{O P e q}$ is cooling efficiency, $H_{h w l, d e m, m, h}$ and $H_{h l, d e m, m, h}$ are hourly hot water load and space heating load.

\section{Evaluation Model}

\section{Economic criterion}

\section{Energy consumption criterion}

$$
C_{\text {total }}=C_{\text {cap }}+C_{O \& M}+C_{\text {fuel }}
$$

Energy consumption criterion can be primary energy consumption and primary energy ratio.

Primary energy consumption $Q$ is equal to the gas consumption of DES $Q_{\text {des,gas }}$ and the equivalent consumption of the electricity purchased $Q_{\text {des,ep }}$.

$$
Q=Q_{\text {des,gas }}+\frac{Q_{\text {des }, e p}}{\eta(1-\varphi)}
$$

where $\varphi$ is average efficiency of traditional coal-fired power plant, $\eta$ is loss rate of transmission line.

Primary energy ratio $P_{E R \text {,des }}$ is ratio of the output power and the primary energy consumption. The larger $P_{E R, \text { des }}$ is, the energy-saving performance is better.

$$
P_{E R, \text { des }}=\frac{Q_{e}+Q_{h}+Q_{c}}{Q_{\text {des,gas }}+\frac{Q_{\text {des }, e p}}{\eta(1-\varphi)}}
$$

where $Q_{e}, Q_{h}, Q_{c}$ are hourly power, heating and cooling output.

\section{Environmental criterion}

Emissions of DES are mainly from gas turbine, gas boiler, internal combustion engine, fuel cell and electricity purchased (equivalent amount of pollutants produced by coal-fired plant). This paper focuses on the emissions of $\mathrm{CO}_{2}$ and $\mathrm{NO}_{\mathrm{x}}[15]$.

\section{Multi-criteria Comprehensive Evaluation Method}

\section{Normalized criteria}

Assume there are $m$ systems to be evaluated, denoted as $\boldsymbol{Y}=\left[y_{1}, y_{2}, \mathrm{~L}, y_{m}\right]$; there are $n$ criteria, denoted as $\boldsymbol{X}=\left[x_{1}, x_{2}, \mathrm{~L}, x_{n}\right]$. The criterion $x_{j}$ corresponding to the system $y_{i}$ is denoted as $a_{i j}$ $(i=1,2, \mathrm{~L}, m, j=1,2, \mathrm{~L}, n)$, then we have criteria matrix $\boldsymbol{A}=\left[a_{i j}\right]_{m \times n}$,

$$
\boldsymbol{A}=\left[\begin{array}{cccc}
a_{11} & a_{12} & \mathrm{~L} & a_{1 n} \\
a_{21} & a_{22} & \mathrm{~L} & a_{2 n} \\
\mathrm{M} & \mathrm{M} & \mathrm{M} & \mathrm{M} \\
a_{m 1} & a_{m 2} & \mathrm{~L} & a_{m n}
\end{array}\right]
$$

For those criteria that we expect them large (the larger, the better), we use (18) to normalize them,

$$
b_{i j}=\frac{x_{i}-\min x_{i}}{\max x_{i}-\min x_{i}}
$$

For those criteria that we expect them small (the smaller, the better), we use (19) to normalize them, 


$$
b_{i j}=\frac{\max x_{i}-x_{i}}{\max x_{i}-\min x_{i}}
$$

After the normalization, $0 \leq b_{i j} \leq 1$. $\boldsymbol{A}$ is normalized to $\boldsymbol{B}$, and matrix $\boldsymbol{P}$ is the normalized matrix.

$$
P_{i j}=b_{i j} /\left(\sum_{j=1}^{m} b_{i j}\right)
$$

\section{Criteria information entropy}

Information entropy has the same properties, uniqueness, additivity and extremality, as thermodynamic entropy. Larger entropy of a criterion means a larger degree of difference, and that will provide more information and play a greater role in the comprehensive evaluation, who will definitely have a larger weight. Entropy method utilizes the information entropy of criteria to define their weights. The information entropy of the criterion $x_{j}$ is:

$$
e_{j}=-k \sum_{i=1}^{m} P_{i j} \ln P_{i j}=-\frac{1}{\ln m} \sum_{i=1}^{m} P_{i j} \ln P_{i j}
$$

\section{Determine the entropy weights and results of comprehensive evaluation}

The entropy weight of the criterion $x_{j}$ is (22) and comprehensive evaluation of the system $y_{i}$ is (23).

$$
\begin{gathered}
\omega_{j}=\left(1-e_{j}\right) /\left[\sum_{j=1}^{n}\left(1-e_{j}\right)\right] \\
v_{\text {value }, i}=\sum_{j=1}^{n} \omega_{j} P_{i j}
\end{gathered}
$$

\section{Examples}

\section{Load}

Take a hotel in Shanghai as an example. Its total floor area is approximately $9600 \mathrm{~m}^{2}$; the roof area is $1600 \mathrm{~m}^{2}$, and since PV system occupies $6 \mathrm{~m}^{2}$ every kilowatt, the maximum capacity of PV system can be about $260 \mathrm{~kW}$. We got the data of hourly loads from DeST. Fig. 1 and Fig. 2 show the load curve of a typical winter day and a typical summer day. Since the optimization of the whole year is too complicated, we suppose each day's loads are the same in one month, and the question is simplified as $288 \mathrm{~h}(12 \times 24)$ instead of $8760 \mathrm{~h}(365 \times 24)$. The system can purchase electricity from the grid but cannot sell electricity to the grid. And the price of electricity is peak-valley price.

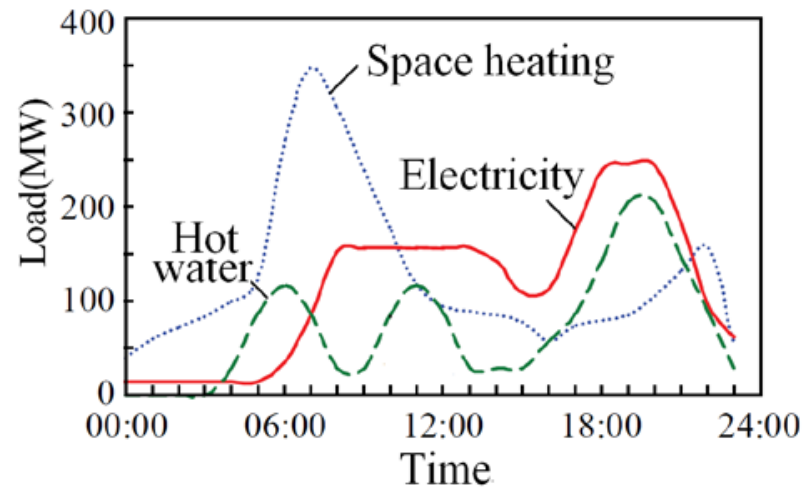

Fig. 1 Hourly load demand in January 1

\section{Optimization results}

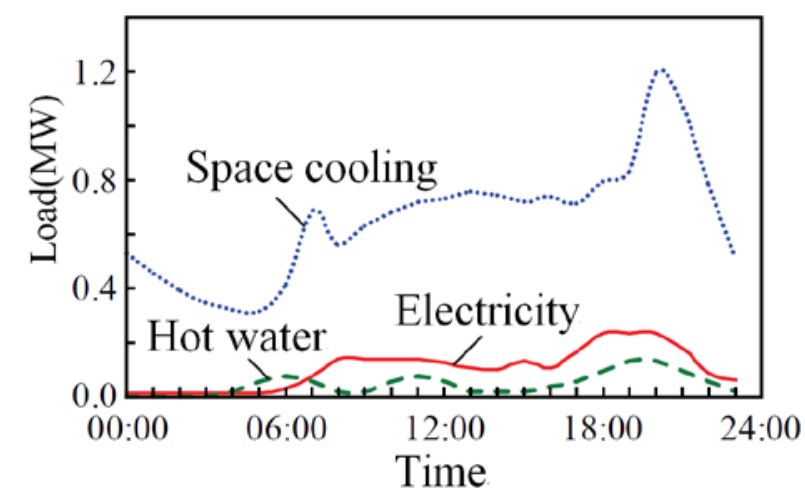

Fig. 2 Hourly load demand in July 1

Without knowing capacity of any device or operating strategy of S4 and S5, we used the software lingo to optimize, and we got the result that the capacity of the internal combustion engine is $180 \mathrm{~kW}$, the gas engine is $152 \mathrm{~kW}$. As for S2 and S3, since the equipment is expensive, the capacity is small, and to simplify the research, we determined the capacity of the power equipment is $150 \mathrm{~kW}$. The configuration is shown in Fig. 3. 
Since the cooling and heating loads didn't change, the capacity of heater exchanger and refrigerator didn't change a lot. The capacity of boilers in S4 and S5 are large, and almost equal to each other, mainly because these two systems both used Lithium bromide absorption refrigeration and the cooling loads were mainly satisfied by the thermal output of systems. S3 and S2 both used electric refrigeration, so the thermal output mainly satisfied heating load, and the capacity of the boiler is small. In addition, heat can be recovered from the generator, so the capacity of the boiler in $\mathrm{S} 3$ is the smallest.

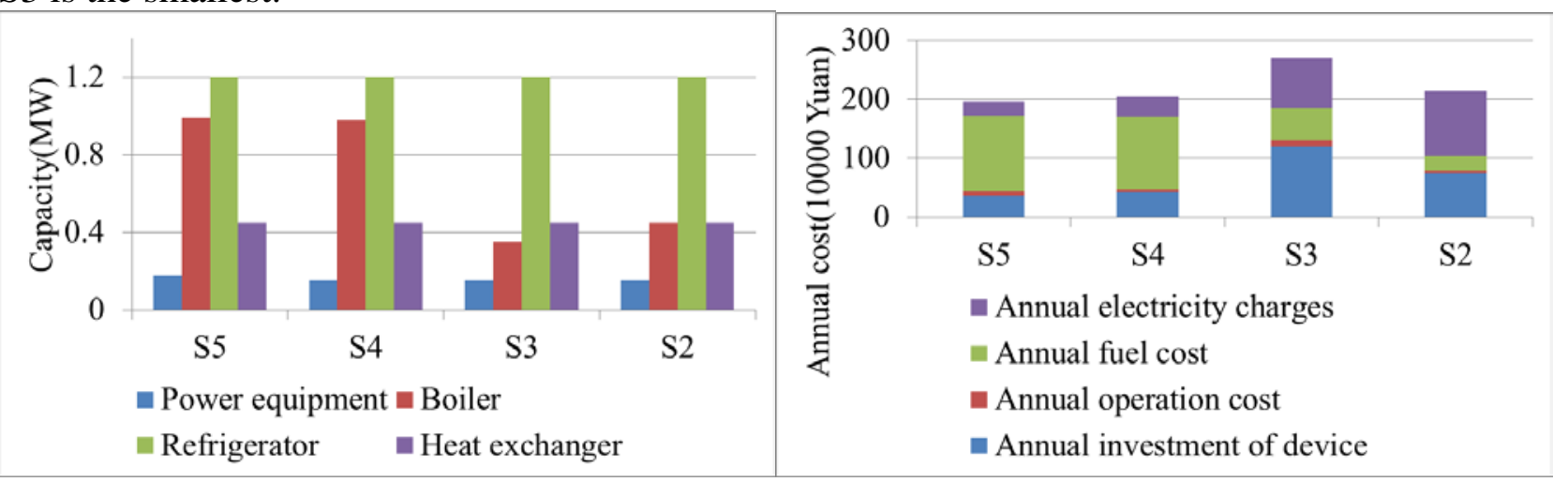

Fig. 3 Optimal configuration of DES

Fig. 4 Annual cost of systems

Annual cost of systems is shown in Fig. 4. The annual cost of S3 is highest because fuel cell is expensive and the cooling load is satisfied by electric refrigeration. S2 has to purchase electricity to avoid the instability of the PV. The costs of S4 and S5 have been affected a lot by the price of gas.

The calculation results of evaluation criteria

After the optimization, we calculated the value of each criterion shown in Table 2.

Table 2 The result of evaluation criteria

\begin{tabular}{ccccccc}
\hline Number & Criterion & S1 & S2 & S3 & S4 & S5 \\
\hline A1 & Investment(Ten thousand Yuan) & 277 & 597 & 829 & 329 & 310 \\
A2 & Operation cost(Ten thousand Yuan) & 189 & 137 & 159 & 159 & 153 \\
A3 & Fuel consumption(MWh) & 5282 & 2622 & 3024 & 4684 & 4516 \\
A4 & Primary energy ratio(\%) & 66.6 & 1342 & 1163 & 75.1 & 77.9 \\
A5 & Annual emission of $\mathrm{CO}_{2}(\mathrm{t})$ & 153.84 & 73.60 & 51.10 & 96.30 & 88.30 \\
A6 & Annual emission of $\mathrm{NO}_{\mathrm{x}}(\mathrm{t})$ & 4.21 & 1.97 & 1.52 & 1.54 & 1.33 \\
\hline
\end{tabular}

The evaluation results of entropy method

Normalize all criteria in the 5 systems, and then we have distribution of all criteria shown in Fig.5. From Fig.5, we can get Fig.6. We can infer that there are huge differences between A4 of different systems, and the corresponding information entropy is smallest; the weight is biggest.

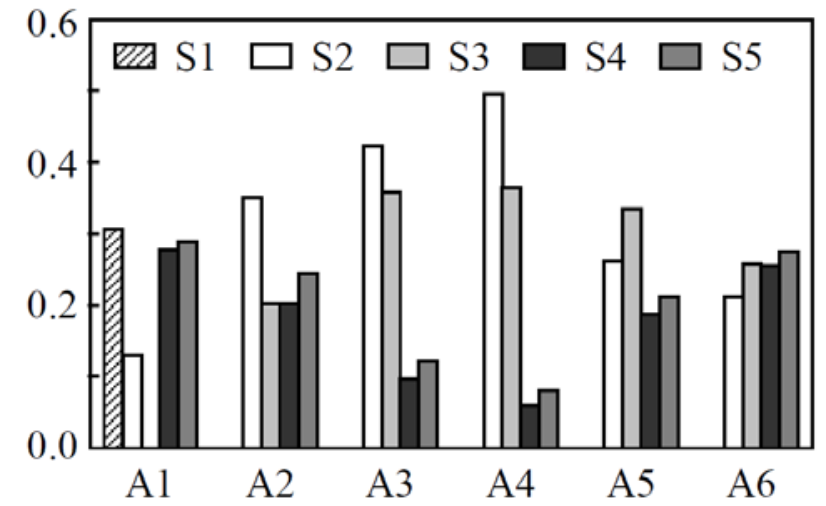

Fig. 5 The distribution of criteria

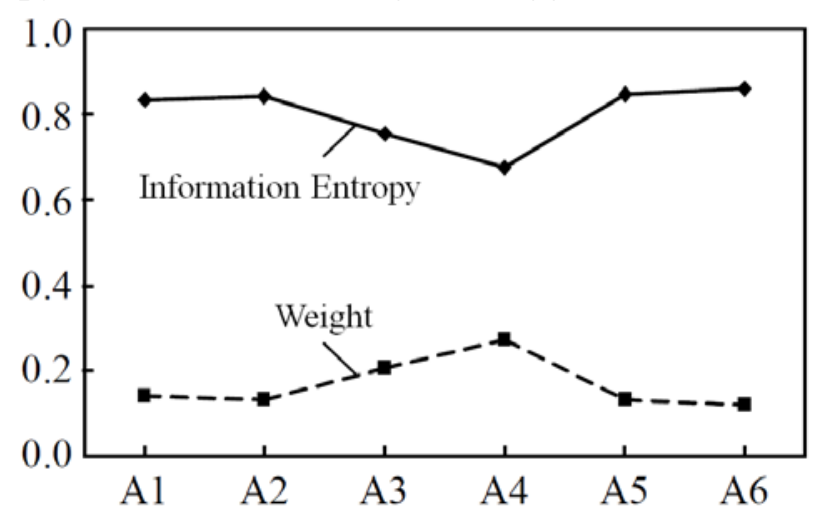

Fig. 6 Entropy and weights of criteria

According to (23), we can evaluate the 5 systems shown in Table 3. And we can come to the conclusion that $\mathrm{S} 2$ is the most optimized one, while S1 is the least one.

Table 3 Evaluation results

\begin{tabular}{cccccc}
\hline Systems & S1 & S2 & S3 & S4 & S5 \\
\hline Evaluation & 0.04 & 0.39 & 0.30 & 0.12 & 0.15 \\
\hline
\end{tabular}




\section{Summary}

This paper changed the optimization design and strategies into a nonlinear optimization problem. The model considered three aspects of criteria, cost, energy consumption and environmental protection. This paper evaluated five common DES and calculated six criteria and corresponding weights. Finally, these systems were evaluated. The result was that considering all three aspects, photovoltaic system is the most optimal scheme.

\section{Acknowledgement}

This paper is sponsored by Science and Technology Project of SGCC (SGTJDK00DWJS1500100).

\section{References}

[1] Wang Xi, Yang Yongping. (2014). Analysis on operation characteristics of the internal combustion engine dual source system. Proceedings of the CSEE, 34(2), 217-224(in Chinese).

[2] Zhang Xiaohui, Chen Zhongxin. (2007). Energy consumption performance of combined heat cooling and power system. Proceedings of the CSEE, 27(5), 93-98(in Chinese).

[3] Ren, H., Zhou, W., \& Gao, W. (2012). Optimal option of distributed energy systems for building complexes in different climate zones in China. Applied Energy, 91(1), 156-165.

[4] Zhou, Z., Liu, P., Li, Z., \& Ni, W. (2013). An engineering approach to the optimal design of distributed energy systems in China. Applied Thermal Engineering, 53(2), 387-396.

[5] Jabbari, B., Tahouni, N., Ataei, A., \& Panjeshahi, M. H. (2013). Design and optimization of CCHP system incorporated into kraft process, using Pinch Analysis with pressure drop consideration. Applied Thermal Engineering, 61(1), 88-97.

[6] Smith, A., Luck, R., \& Mago, P. J. (2010). Analysis of a combined cooling, heating, and power system model under different operating strategies with input and model data uncertainty. Energy and Buildings, 42(11), 2231-2240.

[7] Mago, P. J., \& Chamra, L. M. (2009). Analysis and optimization of CCHP systems based on energy, economical, and environmental considerations.Energy and Buildings, 41(10), 1099-1106.

[8] Cho, H., Mago, P. J., Luck, R., \& Chamra, L. M. (2009). Evaluation of CCHP systems performance based on operational cost, primary energy consumption, and carbon dioxide emission by utilizing an optimal operation scheme. Applied Energy, 86(12), 2540-2549.

[9] Ren, H., Gao, W., Zhou, W., \& Nakagami, K. I. (2009). Multi-criteria evaluation for the optimal adoption of distributed residential energy systems in Japan. Energy Policy, 37(12), 5484-5493.

[10] Yang, H., Xiong, T., Qiu, J., Qiu, D., \& Dong, Z. Y. (2015). Optimal operation of DES/CCHP based regional multi-energy prosumer with demand response.Applied Energy.

[11]Wang, J. J., Jing, Y. Y., \& Zhang, C. F. (2010). Optimization of capacity and operation for CCHP system by genetic algorithm. Applied Energy, 87(4), 1325-1335.

[12]Wu, J. Y., Wang, J. L., \& Li, S. (2012). Multi-objective optimal operation strategy study of micro-CCHP system. Energy, 48(1), 472-483.

[13] Maraver, D., Sin, A., Sebastián, F., \& Royo, J. (2013). Environmental assessment of CCHP (combined cooling heating and power) systems based on biomass combustion in comparison to conventional generation. Energy, 57, 17-23. 
[14]Tian, Z., Niu, J., Lu, Y., He, S., \& Tian, X. (2016). The improvement of a simulation model for a distributed CCHP system and its influence on optimal operation cost and strategy. Applied Energy, 165, 430-444.

[15]Li, C. Z., Shi, Y. M., \& Huang, X. H. (2008). Sensitivity analysis of energy demands on performance of CCHP system. Energy Conversion and Management, 49(12), 3491-3497. 